\title{
Vibration Analysis of the Pipeline with Internal Unsteady Fluid Flow by Using Spectral Element Method
}

\author{
스펙트럴요소법을 이용한 내부 비정상류를 갖는 파이프에 대한 진동해석\#
}

\section{Bosung Seo, Jooyong Cho and Usik Lee}

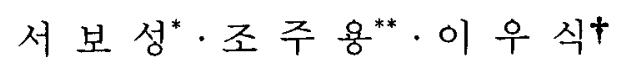

(Received December 5, 2005 ; Accepted March 14, 2006)

Key Words : Pipe-dynamics(파이프 동력학), Unsteady Fluid Flow(비정상 유동), Spectral Element Method (스펙트럴요소법)

\begin{abstract}
In this paper, a spectral element model is developed for the uniform straight pipelines conveying internal unsteady fluid flow. The spectral element matrix is formulated by using the exact frequency-domain solutions of the pipe-dynamics equations. The spectral element dynamic analysis is then conducted to evaluate the accuracy of the present spectral element model and to investigate the vibration characteristics and internal fluid characteristics of an example pipeline system.
\end{abstract}

요 약

이 논문에서는 내부에 비정상 유동이 흐르는 균일한 직선 파이프에 대한 스펙트럴요소모델을 개발하였다. 개발된 스펙트럴요소모델에 대한 스펙트럴요소행렬은 주파수 영역에서 구한 파이프 동역학 방정식의 엄밀해 를 이용하여 유도되었다. 이 스펙트럴요소모델의 정확성을 평가하고 한 예제 파이프 계의 진동특성과 파이프 내부 유동특성을 고찰하기 위하여 스펙트럴 동역학 해석을 수행하였다.

\section{Introduction}

There have been extensive studies on the modeling and analysis of the flow-induced vibrations of pipeline systems over the past

† 책임저자 ; 정회원, 인하대학교 기계공학과

E-mail : ulee@inha.ac.kr

Tel : (032) 860-7318, Fax : (032) 866-143

* 정회원, 인하대학교 대학원 기계공학과

** 인하대학교 대학원 기계공학과

\# 이 논문은 2005년 추계 소음진동학술대회에서 우수논문 으로 추천되었음. half-century: an extensive review on this subject can be found in Paidoussis and $\mathrm{Li}^{(1)}$. In most existing pipe-dynamics theories, the structural vibration of pipeline itself has been the main concern, neglecting the transient dynamics of internal fluid which should be coupled with the structural vibration of pipeline. To account for the effects of the coupling between the pipeline vibration and internal unsteady fluid flow, Lee et al. ${ }^{(2)}$ derived a set of coupled dynamics equations for the axial, radial, and transverse vibrations of pipeline as well as for the transients of unsteady internal fluid pressure and velocity. The coupled 
pipe-dynamic equations were further generalized by including the circumferential strain effect caused by the internal fluid pressure ${ }^{(3)}$ and, later on, by including the radial shell vibration and initial axial tension ${ }^{(4)}$.

In the literature, the dynamic stiffness method based on FFT (fast Fourier transforms) is often named spectral element method $(\mathrm{SEM})^{(6,7)}$. Because the exact dynamic stiffness matrix is formulated from the exact dynamic shape functions which satisfy the governing equations of motion, it represents the dynamic behavior of a structural element exactly. Thus, the SEM is often justifiably referred to as an exact solution method ${ }^{(5-7)}$.

The purposes of the present paper are (1) to develop a spectral element model for the axial and transverse vibrations of a pipeline conveying internal unsteady fluid flow, and (2) to conduct spectral element analysis to investigate the structural dynamic characteristicsand the internal fluid transients of an example pipeline problem.

\section{Equations of Motions}

We consider a straight pipeline subject to a small amplitude vibration. The equations of motion for a pipeline and the relevant boundary conditions can be derived from the Hamilton's principle. The kinetic ener-gy $T$ and the potential energy $U$ for the pipeline system are given by

$$
\begin{aligned}
T & =\frac{m_{p}}{2} \int_{0}^{L}\left(\dot{u}^{2}+\dot{w}^{2}\right) d x \\
U & =\frac{E A_{p}}{2} \int_{0}^{L}\left\{\frac{T_{o}}{E A_{p}}+\left(u^{\prime}+\frac{1}{2} u^{\prime 2}+\frac{1}{2} w^{\prime 2}\right)\right\}^{2} d x \\
& +\frac{E I_{p}}{2} \int_{0}^{L} w^{\prime \prime 2} d x
\end{aligned}
$$

$\delta W$ is the virtual work done by the flow-induced forces acting on the pipe wall and by the resultant forces and moments applied at the boundaries.

Introducing Eq. (1) and $\delta W$ into Hamilton's principle and integratingby parts gives

$$
\begin{gathered}
E I_{p} w^{\prime \prime \prime}+\left(p A-T_{o}+m_{w} c^{2}\right) w^{\prime \prime}+p^{\prime} A w^{\prime} \\
+m_{w}\left(2 c \ddot{w}^{\prime}+\dot{c}^{\prime}+c c^{\prime} w^{\prime}\right)+m \ddot{w}=0 \\
\left(E A_{p}+T_{o}\right) u^{\prime \prime}-m_{p} \ddot{u}+m_{w} g_{Y} w^{\prime}+m_{w} \frac{f}{2 D} c^{2}=0
\end{gathered}
$$

By applying the Newton's law of motion to the control volume (fluid element), the equations of fluid can be obtained as

$$
\begin{aligned}
& c^{\prime \prime}-\frac{1}{a^{2}} \dot{c} c^{\prime}-\frac{1}{a^{2}} c \dot{c}^{\prime}-\frac{1}{a^{2}} \ddot{c}-\frac{f}{a^{2} D} c \dot{c} \\
& -\frac{g_{Y}}{a^{2}} \dot{w}^{\prime}-2 v \dot{u}^{\prime \prime}-\frac{1}{a^{2}} \dot{c} \dot{u}^{\prime}-\frac{1}{a^{2}} c \ddot{u}^{\prime}=0 \\
& \dot{p} A+a^{2} m_{w}\left(c^{\prime}-2 v \dot{u}^{\prime}\right)=0
\end{aligned}
$$

Equations (2) and (3) represent a set of coupled nonlinear pipe-dynamics equations for the pipeline conveying internal unsteady fluid flow. To linearlize the pipe-dynamics equations, the fluid velocity and pressure are assumed as

$$
c(x, t)=c_{o}+c_{d}(x, t), \quad p(x, t)=p_{o}+p_{d}(x, t)
$$

where $c_{d}(x, t)$ and $p_{d}(x, t)$ represent the small perturbations with respect to constant steady-state values $c_{o}$ and $p_{o}$, respectively. Accordingly one may assume that $c_{d}<c_{o}$ and $p_{d}$

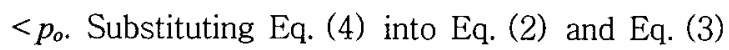
and neglecting small nonlinear terms a set of linearized pipe-dynamics equations as follows:

$$
\begin{aligned}
& E I_{p} w^{\prime \prime \prime}+\left(p_{o} A-T_{o}+m_{w} c_{o}^{2}\right) w^{\prime \prime}+2 m_{w} c_{o} \dot{w}^{\prime}+m \ddot{w}=0 \\
& \left(E A_{p}+T_{o}\right) u^{\prime \prime}-m_{p} \ddot{u}+m_{w} g_{Y} w^{\prime}+m_{w} \frac{f}{D} c_{o} c_{d}+m_{w} \frac{f}{2 D} c_{o}^{2}=0 \\
& c_{d}^{\prime \prime}-\frac{c_{o}}{a^{2}} \dot{c}_{d}^{\prime}-\frac{f}{a^{2} D} c_{o} \dot{c}_{d}-\frac{\ddot{c}}{a^{2}}-\frac{g_{Y}}{a^{2}} \dot{w}^{\prime}-2 v \dot{u}^{n}-\frac{c_{o}}{a^{2}} \ddot{u}^{\prime}=0 \\
& \dot{p}_{d} A+a^{2} m_{w}\left(c_{d}^{\prime}-2 v \dot{u}^{\prime}\right)=0
\end{aligned}
$$




\section{Formulation of Spectral Element Model}

The general solutions of Eq. (5) can be assumed in the spectral forms as

$$
\begin{aligned}
& w(x, t)=\sum_{n=1}^{N} W_{n}(x) e^{i \omega_{0} t}, \quad u(x, t)=\sum_{n=1}^{N} U_{n}(x) e^{i \omega_{,} t} \\
& c_{d}(x, t)=\sum_{n=1}^{N} C_{n}(x) e^{i \omega_{0},}, \quad p_{d}(x, t)=\sum_{n=1}^{N} P_{n}(x) e^{i \omega_{0}, t}
\end{aligned}
$$

where $W_{n}(x), U_{n}(x), C_{n}(\mathrm{x})$ and $P_{n}(x)$ are the spatially dependent spectral components of $w(x, t), u(x, t), c_{d}(x, t)$ and $p_{d}(x, t)$, respectively. Substituting Eq. (6) into Eq. (5) yields

$$
\begin{aligned}
& a_{1} W^{\prime \prime \prime}+a_{2} W^{\prime \prime}+a_{3} i \omega W^{\prime}-a_{4} \omega^{2} W=0 \\
& b_{1} U^{\prime \prime}-b_{2} \omega^{2} U+b_{3} W^{\prime}+b_{4} C+b_{5}=0 \\
& C^{\prime \prime}+c_{1} i \omega C^{\prime}+\left(c_{2} i \omega-c_{3} \omega^{2}\right) C \\
& \quad-c_{4} i \omega W^{\prime}+c_{5} i \omega U^{\prime \prime}-c_{1} \omega^{2} U^{\prime}=0 \\
& i \omega P+d_{1}\left(C^{\prime}+c_{5} i \omega U^{\prime}\right)=0
\end{aligned}
$$

where the following definitions are used:

$$
\begin{aligned}
& a_{1}=E I_{p}, a_{2}=p_{o} A-T_{o}+m_{w} c_{o}^{2}, a_{3}=2 m_{w} c_{o}, a_{4}=m \\
& b_{1}=E A_{p}+T_{o}, b_{2}=-m_{p}, b_{3}=m_{w} g_{Y}, b_{4}=m_{w} \frac{f}{D} c_{o} \\
& b_{5}=m_{w} \frac{f}{2 D} c_{o}^{2}, c_{1}=-\frac{c_{o}}{a^{2}}, c_{2}=-\frac{f}{a^{2} D} c_{o}, c_{3}=-\frac{1}{a^{2}} \\
& c_{4}=-\frac{g_{Y}}{a^{2}}, c_{5}=-2 v, d_{1}=\rho_{w} a^{2}
\end{aligned}
$$

The general solutions of Eq. (7) are assumed as

$$
\begin{aligned}
W(x) & =\bar{W} e^{i k x}, U(x)=\bar{U} e^{i k x} \\
C(x) & =\bar{C} e^{i k x}, P(x)=\bar{P} e^{i k x}
\end{aligned}
$$

where $k$ is the wavenumber. Substituting Eq. (9) into Eq. (7) gives an eigenvalue problem from which one can obtain two dispersion equations. The first dispersion equation provides the wavenumbers $\left(k_{1}, k_{2}, k_{3}, k_{4}\right)$ for the beam bending vibration modes, whereas the second dispersion equation provides the wavenumbers $\left(k_{5}, k_{6}, k_{7}, k_{8}\right)$ for the axial vibration-fluid velocity coupling modes. By using the eight wavenumbers, the general solutions can be expressed as following forms:

$$
\begin{aligned}
& W(x)=\sum_{j=1}^{4} \bar{W}_{j} e^{i k_{j} x}=\left[\mathbf{e}_{\mathbf{w}}(x)\right]\left\{\boldsymbol{\varphi}_{\mathrm{w}}\right\} \\
& U(x)=\sum_{j=1}^{4} \bar{U}_{j} e^{i k_{j+4} x}=\left[\mathbf{e}_{\mathrm{uc}}(x)\right]\left\{\boldsymbol{\varphi}_{\mathrm{uc}}\right\} \\
& C(x)=\sum_{j=1}^{4} \alpha_{j} \bar{U}_{j} e^{i k_{j+4} x}=\left[\mathbf{e}_{\mathrm{uc}}(x)\right]\left[\mathbf{D}_{\mathrm{uc}}\right]\left\{\boldsymbol{\varphi}_{\mathrm{uc}}\right\}
\end{aligned}
$$

and $\{\boldsymbol{w}\}$ and $\left\{\boldsymbol{u}_{c}\right\}$ are constant vectors to be eliminated later on. Now, consider a finite pipeline element of length $l$. The spectral nodal degrees of freedom (simply, spectral nodal DOFs) are defined by

$W(0)=W_{1}, \Theta(0)=\Theta_{1}, U(0)=U_{1}, C(0)=C_{1}, P(0)=P_{1}$ $W(l)=W_{2}, \Theta(l)=\Theta_{2}, \quad U(l)=U_{2}, C(l)=C_{2}, \quad P(l)=P_{2}$

where $\theta(x)=W^{\prime}(x)$ denotes the slope. Substituting Eq. (10) into Eq. (11) gives the relationships between the spectral nodal DOFs vectors and the constants vectors as follows:

$$
\left\{\boldsymbol{d}_{\boldsymbol{w}}\right\}=\left[\boldsymbol{H}_{\boldsymbol{w}}(\omega)\right]\left\{\boldsymbol{\varphi}_{w}\right\}, \quad\left\{\boldsymbol{d}_{\boldsymbol{u c}}\right\}=\left[\boldsymbol{H}_{u c}(\omega)\right]\left\{\boldsymbol{\varphi}_{\boldsymbol{~ u c}}\right\}
$$

where

$$
\begin{aligned}
& \left\{\boldsymbol{d}_{w}\right\}=\left\{W_{1} \theta_{1} W_{2} \theta_{2}\right\}^{\mathrm{T}} \\
& \left\{\boldsymbol{d}_{\boldsymbol{u c}}\right\}=\left\{U_{1} U_{2} C_{1} C_{2}\right\}^{\mathrm{T}} \\
& {\left[\boldsymbol{H}_{w}(\omega)\right]=\left[\begin{array}{cccc}
1 & 1 & 1 & 1 \\
i k_{1} & i k_{2} & i k_{3} & i k_{4} \\
e_{1} & e_{2} & e_{3} & e_{4} \\
i k_{1} e_{1} & i k_{2} e_{2} & i k_{3} e_{3} & i k_{4} e_{4}
\end{array}\right]} \\
& {\left[\boldsymbol{H}_{u c}(\omega)\right]=\left[\begin{array}{cccc}
1 & 1 & 1 & 1 \\
e_{5} & e_{6} & e_{7} & e_{8} \\
\alpha_{1} & \alpha_{2} & \alpha_{3} & \alpha_{4} \\
\alpha_{1} e_{5} & \alpha_{2} e_{6} & \alpha_{3} e_{7} & \alpha_{4} e_{8}
\end{array}\right]}
\end{aligned}
$$


with

$$
e_{j}=e^{i k, I}
$$$$
(j=1,2,3,8)
$$

From Eqs. (10) and (12), one may obtain

$$
\begin{aligned}
& W(x)=\left[\boldsymbol{N}_{w}(x ; \omega)\right]\left\{\boldsymbol{d}_{w}\right\} \\
& U(x)=\left[\boldsymbol{N}_{u}(x ; \omega)\right]\left\{\boldsymbol{d}_{u c}\right\} \\
& C(x ;)=\left[\boldsymbol{N}_{c}(x ; \omega)\right]\left\{\boldsymbol{d}_{u c}\right\}
\end{aligned}
$$

where

$$
\begin{aligned}
& {\left[\boldsymbol{N}_{w}(x ; \omega)\right]=\left[\boldsymbol{e}_{w}(x)\right]\left[\boldsymbol{H}_{w}(\omega)\right]^{-1}} \\
& {\left[\boldsymbol{N}_{u}(x ; \omega)\right]=\left[\boldsymbol{e}_{u c}(x)\right]\left[\boldsymbol{H}_{u c}(\omega)\right]^{-1}} \\
& {\left[\boldsymbol{N}_{c}(x ; \omega)\right]=\left[\boldsymbol{e}_{u c}(x)\right]\left[\boldsymbol{D}_{u c}(\omega)\right]\left[\boldsymbol{H}_{u c}(\omega)\right]^{-1}}
\end{aligned}
$$

The variational approach can be used to formulate the spectral element matrix by using the displacements and fluid fields given by Eq. (15). Substituting Eq. (16) into the weak form of Eq. (12) and taking some manipulation gives an equation in the form as

$$
[\boldsymbol{S}(\omega)]\{d\}=\{\boldsymbol{f}\}
$$

where $\{d\}$ and $\{f\}$ are the spectral nodal DOFs vector and the spectral nodal forces vector, respectively, and $[S(\omega)]$ is the spectral element matrix defined in the form of

$$
[S(\omega)]=\left[\begin{array}{cc}
s_{11} & 0 \\
S_{21} & s_{22}
\end{array}\right]
$$

Assembling the spectral element equation (17) and then applying the appropriate boundary conditions will provide the dynamic equation of a global system.

\section{Numerical Results and Discussions}

A uniform straight pipeline simply supported at both ends is considered as an illustrative example problem. The pipeline has the length $L=6000 \mathrm{~mm}$, internal diameter $D=32.12$ $\mathrm{mm}$, thickness $t=1.4 \mathrm{~mm}$, Young's modulus $E$
$=117 \mathrm{GPa}$, and mass density of pipeline $m_{p}=$ $0.0515 \mathrm{~kg} / \mathrm{m}$. The mass density of fluid is $m_{w}$ $=1.318 \mathrm{~kg} / \mathrm{m}$. It is assumed that the pipeline is subject to the constant axial tension $T_{0}=$ $82 \mathrm{~N}$.

The high accuracy of the present spectral element model is verified first by comparing the eigenfrequencies obtained by using the present SEM with those obtained by the conventional FEM and also with the exact analytical results from Blevins ${ }^{(8)}$.

Table 1 shows the eigenfrequencies of the lowest four transverse displacement (bending) modes, the first axial displacement mode, and the first fluid mode obtained by the present SEM, the FEM, and the exact theoretical result from Blevins ${ }^{(8)}$. The FEM results are obtained by increasing the number of finite elements from 10 to 100 , as shown in Table 1 . When the (steady-state) flow velocity is $c_{0}=0 \mathrm{~m} / \mathrm{s}$, the eigenfrequencies obtained by the present SEM are found to be identical to the exact ones by Blevins ${ }^{(8)}$.

It can be also observed from Table 1 that the FEM results converge to the SEM results at all flow velocities as the number of finite elements is increased. For the present example problem, more than fifty finite elements should be used in FEM to achieve the same high accuracy. of the fifth eigenfrequency by SEM.

It can be also observed from Table 1 that the real parts of eigenfrequencies (i.e., natural frequencies) are reduced in magnitude as the fluid velocity is increased. The first natural frequency becomes zero at $c_{0}=28.65 \mathrm{~m} / \mathrm{s}$ at which the divergence instability, occurs as discussed in the following.

Figure 1 shows the dynamic responses of the transverse displacement in the frequency and time domains obtained by the present SEM and the FEM. It is assumed that the fluid 
velocity is $c_{0}=10 \mathrm{~m} / \mathrm{s} . T_{0}$ excite the pipeline, a point load $f(t)$ of magnitude $1 \mathrm{kN}$ is applied for 0.001 seconds at $x=L / 5$. The dynamic responses are then measured at the excitation point, i.e., $x=L / 5$. It is certain from Fig. 1 that the dynamic responses obtained by the FEM converge to the SEM results as the number of finite elements used in the FEM is

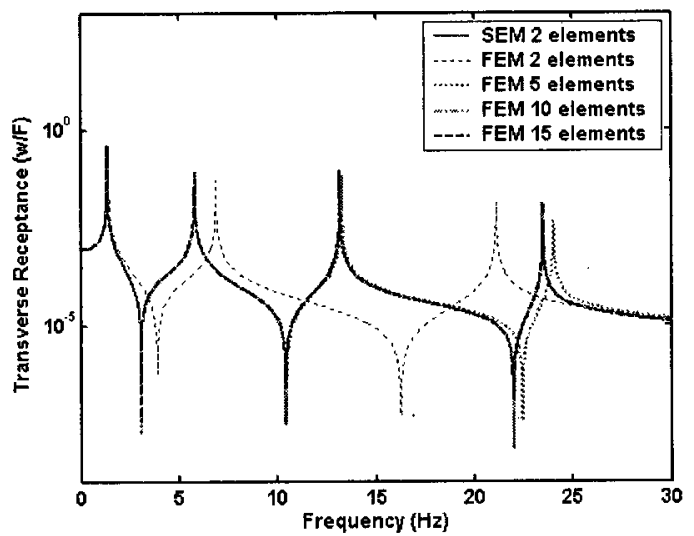

Fig. 1 Ttransverse displacements at $x=L / 5$ in the frequency domain obtained by the present SEM and FEM
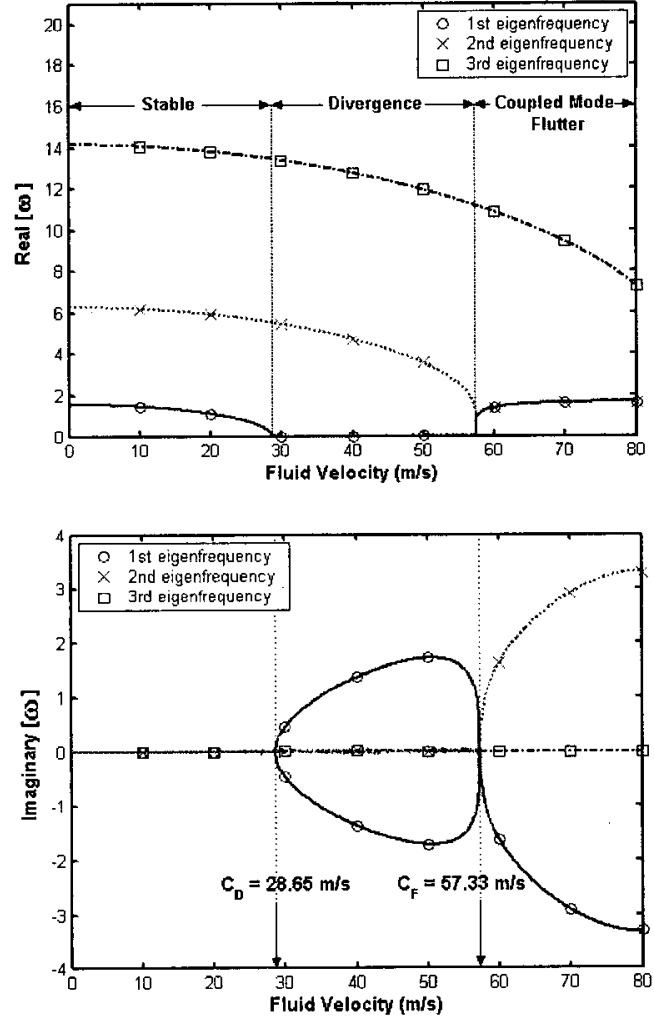

Fig. 2 Fluid velocity dependence of the lowest three eigenfrequencies of pipeline

Table 1 Eigenfrequencies $(\mathrm{Hz})$ of the pipeline obtained by the present SEM, FEM and the exact theory ${ }^{(8)}$

\begin{tabular}{|c|c|c|c|c|c|c|c|c|}
\hline Fluid velocity $(\mathrm{m} / \mathrm{s})$ & Method & $N$ & $\omega_{1}^{\mathrm{f} w)}$ & $\omega_{2}^{f w\}}$ & $\omega_{3}^{(w)}$ & $\omega_{4}^{(w)}$ & $\omega_{6}^{(c)}$ & $\omega_{12}^{(\mu)}$ \\
\hline \multirow{6}{*}{0} & Exact [8] & & 1.47 & 5.89 & 13.26 & 23.57 & 51.98 & 150.73 \\
\hline & SEM & 1 & 1.47 & 5.89 & 13.26 & 23.57 & 51.98 & 150.73 \\
\hline & \multirow{4}{*}{ FEM } & 10 & 1.47 & 5.89 & 13.26 & 23.57 & 51.98 & 157.39 \\
\hline & & 20 & 1.47 & 5.89 & 13.26 & 23.57 & 51.98 & 150.77 \\
\hline & & 50 & 1.47 & 5.89 & 13.26 & 23.57 & 51.98 & 150.74 \\
\hline & & 100 & 1.47 & 5.89 & 13.26 & 23.57 & 51.98 & 150.74 \\
\hline \multirow{5}{*}{10} & SEM & 1 & 1.37 & 5.81 & 13.18 & 23.50 & $52.00+0.47 i$ & $150.74+0.02 i$ \\
\hline & \multirow{4}{*}{ FEM } & 10 & 1.37 & 5.81 & 13.18 & 23.50 & $52.03+0.47 i$ & $150.89+0.02 i$ \\
\hline & & 20 & 1.37 & 5.81 & 13.18 & 23.50 & $51.99+0.47 i$ & $150.77+0.02 i$ \\
\hline & & 50 & 1.37 & 5.81 & 13.18 & 23.50 & $51.98+0.47 i$ & $150.74+0.02 i$ \\
\hline & & 100 & 1.37 & 5.81 & 13.18 & 23.50 & $51.98+0.47 i$ & $150.74+0.02 i$ \\
\hline \multirow{5}{*}{28.65} & SEM & 1 & 0.00 & 5.18 & 12.59 & 22.93 & $52.00+1.18 i$ & $150.74+0.04 i$ \\
\hline & \multirow{4}{*}{ FEM } & 10 & 0.00 & 5.18 & 12.59 & 22.93 & $52.02+1.18 i$ & $150.89+0.04 i$ \\
\hline & & 20 & 0.00 & 5.18 & 12.59 & 22.93 & $51.98+1.18 i$ & $150.77+0.04 i$ \\
\hline & & 50 & 0.00 & 5.18 & 12.59 & 22.93 & $51.97+1.18 i$ & $150.74+0.04 i$ \\
\hline & & 100 & 0.00 & 5.18 & 12.59 & 22.93 & $51.97+1.18 i$ & $150.74+0.04 i$ \\
\hline
\end{tabular}

Note $: N=$ number of finite elements; $(w)=$ transverse displacement mode; $(u)=$ axial displacement mode $;(c)$ = fluid mode 


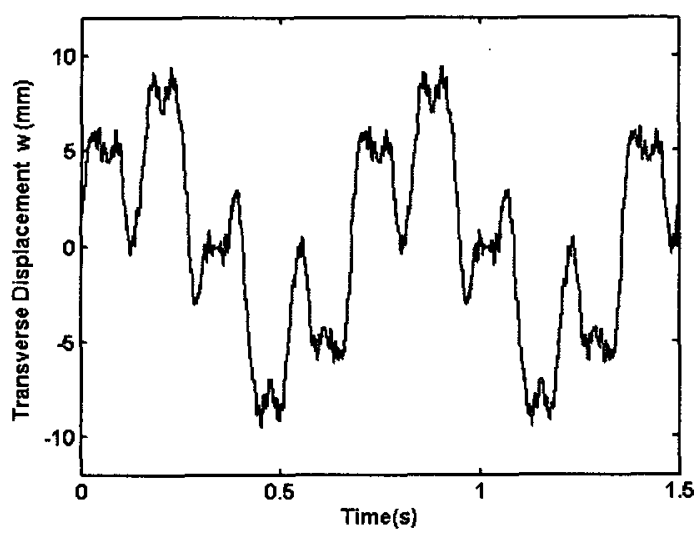

(a) $c_{0}=0 \mathrm{~m} / \mathrm{s}$

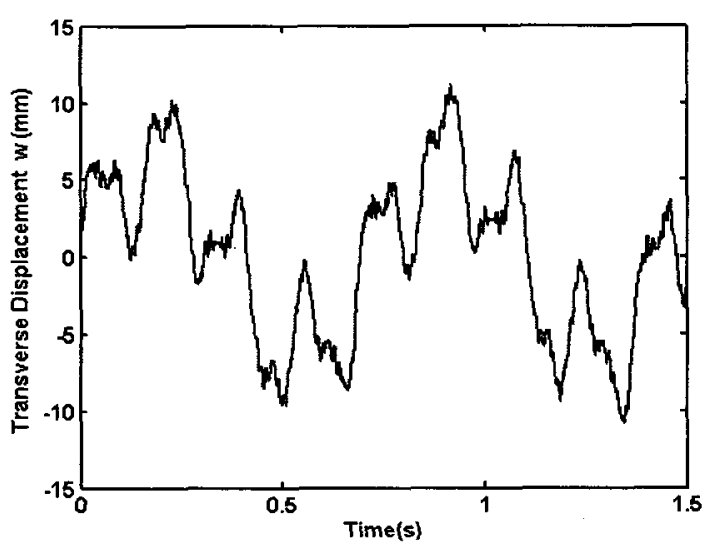

(b) $c_{0}=10 \mathrm{~m} / \mathrm{s}$

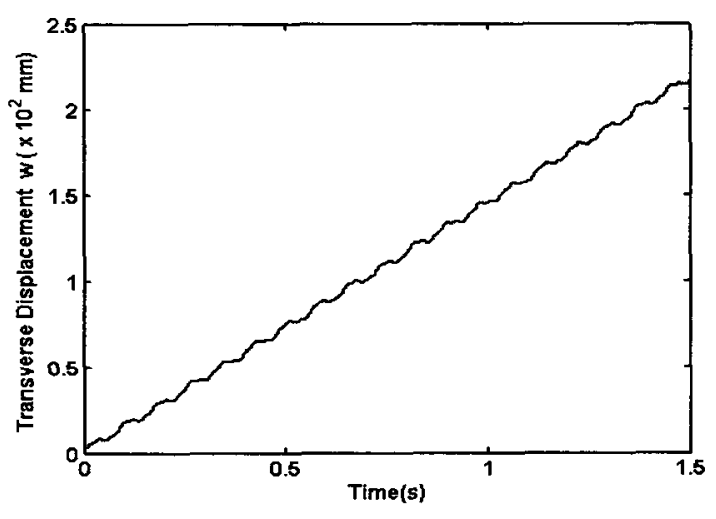

(c) $c_{0}=28.65 \mathrm{~m} / \mathrm{s}$

Fig. 3 The transverse displacement of the pipeline at $x=L / 5$ vs. the fluid velocity $c_{0}$

increased. Thus, both the results shown in both Table 1 and Fig. 1 prove the high accuracy of the present spectral element model.
Figure 2 shows the fluid velocity dependence of the real and imaginary parts of the lowest three eigenfrequencies. The divergence instability may occur when the imaginary part of an eigenfrequency is negative and the real part is zero, whereas the flutter instability may occur when the imaginary part is negative, but the real part is not zero. For the present example problem, Fig. 2 shows that the divergence instability occurs in the first bending mode at $c_{0}=28.65 \mathrm{~m} / \mathrm{s}$ (i.e., divergence velocity, $c_{D}$ ), and the flutter instability occurs in the coupled mode of the first and second bending modes at $c_{0}=57.33$ $\mathrm{m} / \mathrm{s}$ (i.e., flutter velocity, $c_{\mathrm{F}}$ ).

Figure 3 shows the time histories of the transverse displacement measured at $x=L / 5$ for three different fluid velocities including the divergence velocity. As expected, the transverse displacement diverges as the flow velocity gets closer to the divergence velocity $c_{\mathrm{D}}=28.65 \mathrm{~m} / \mathrm{s}$.

When the fluid velocity at the inlet is controlled by $c_{0}=10(1+0.001 \sin 104 \pi t) \mathrm{m} / \mathrm{s}$, the axial displacement and perturbed fluid velocity are shown in Fig. 4. Figure 4 shows that all responses tend to increase with time. This is because the excitation frequency of the inlet fluid velocity $52 \pi$ almost coincides with the first natural frequency of the fluid when co $=10 \mathrm{~m} / \mathrm{s}$ (see Table 1) so that a resonance phenomenon occurs.

\section{Conclusions}

In this study, a spectral element model is developed for the straight pipelines conveying internal unsteady fluid. The high accuracy of the spectral element model is then proved by comparing the eigenfrequencies obtained by the present SEM with those obtained by conventional FEM. Finally, the spectral element 
analysis is conducted to investigate the stability and forced vibration responses of an example pipeline conveying internal unsteady fluid flow.

\section{References}

(1) Païdoussis, M. P. and Li, G. X., 1993, “ Pipes Conveying Fluid: A Model Dynamical Problem," Journal of Fluids and Structures, Vol. 7, pp. 137-204.

(2) Lee, U., Pak, C. H. and Hong, S. C., 1995, "The Dynamics of a Piping System with Internal Unsteady Flow," Journal of Sound and Vibration, Vol. 180, No. 2, pp. 297 311.

(3) Lee, U. and Kim, J., 1999, "Dynamics of Branched Pipeline Systems Conveying Internal Unsteady Flow," Journal of Vibration and Acoustics, Vol. 121, pp. 114 122.
(4) Gorman, D. G., Reese, J. M. and Zhang, Y. L., 2000, "Vibration of a Flexible Pipe Conveying Viscous Pulsating Fluid Flow," Journal of Sound and Vibration, Vol. 230, No. 2, pp. 379 392.

(5) Banerjee, J. R., 1997, "Dynamic Stiffness Formulation for Structural Elements: A General Approach," Computers \& Structures, Vol. 63, No. 1, pp. 101 103.

(6) Doyle, J. F., 1997, Wave Propagation in Structures: Spectral Analysis Using Fast Discrete Fourier Transforms, 2nd ed, New York, Springer-Verlag.

(7) Lee, U., Kim, J. and Leung, A. Y. T., 2000, "The Spectral Element Method in Structural Dynamics," The Shock and Vibration Digest, Vol. 32, No. 6 , pp. $451 \sim 465$.

(8) Blevins, R. D., 1979, Formulas for Natural Frequency and Mode Shape, New York, Van Nostrand Reinhold Company. 